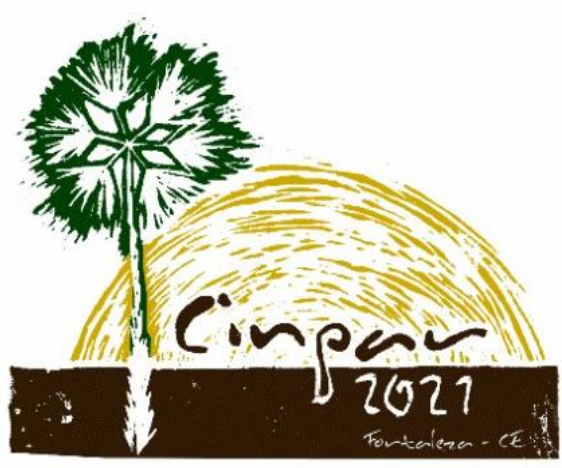

XVII Congresso Internacional sobre Patologia e Reabilitação das Construções

XVII Congreso Internacional sobre Patología y Rehabilitación de las Construcciones

XVII International Conference on Pathology and Constructions Rehabilitation

FORTALEZA (Brasil), 3 a 5 de junho de 2021 https://doi.org/10.4322/CINPAR.2021.084

\title{
Manifestações patológicas em sistema de drenagem de edificações devido à elevação do lençol freático - Estudo de caso em Salvador - BA
}

\section{Pathological manifestations in drainage system of buildings due to the elevation of groundwater level - Case study in Salvador - BA}

\author{
Francisco Gabriel Santos SILVA ${ }^{1}$, Vinícius Almeida COELHO ${ }^{2}$, Luanne Bastos de Britto BARBOSA ${ }^{3}$ \\ ${ }^{1}$ Universidade Federal da Bahia, Escola Politécnica - Departamento de Construção e Estruturas, Brasil, \\ fgabriel.ufba@gmail.com \\ ${ }^{2}$ Universidade Federal da Bahia, Escola Politécnica - Programa de Pós-graduação em Engenharia Civil, Brasil, \\ mrvoelho@gmail.com \\ ${ }^{3}$ Universidade Federal da Bahia, Escola Politécnica - Programa de Pós-graduação em Engenharia Civil, Brasil, \\ lubastosb@gmail.com
}

\begin{abstract}
Resumo: Dentre as principais patologias que acometem as edificações está a infiltração, capaz de promover uma série de danos e comprometer o desempenho e segurança dos sistemas construtivos. Diversos são os mecanismos que atuam para o ingresso da umidade, sendo aqueles decorrentes da chuva, condensação e ascensão capilar os mais corriqueiros. No entanto, também há situações em que o lençol freático é raso nos entornos da edificação ou esta possui níveis de subsolo próximos a tal camada, cenário onde a ocorrência de chuvas intensas e intervenções por parte de terrenos vizinhos pode vir a provocar a elevação do nível de água e o surgimento de manifestações patológicas. Neste cenário, o presente estudo de caso tem como objetivo avaliar as manifestações presentes no sistema de drenagem de um edifício hospitalar na cidade de Salvador - BA que utiliza sistema de reservatório de nível para controle da profundidade do lençol freático, observando-se que o nível de água na região da edificação é raso e há histórico da ocorrência de afloramentos durante o período de chuvas intensas. Para diagnóstico das patologias foi realizada visita in loco com verificação e mapeamento de todo o sistema de drenagem e poços de elevadores da edificação, procedendose com registro fotográfico, teste de pHmetria para identificação de infiltrações. Após análise dos problemas encontrados, são apresentadas as possíveis causas das patologias identificadas, onde foi possível observar a influência ativa das condições climáticas e do comportamento das edificações vizinhas para ocorrência dos fenômenos identificados. Ao final, são sugeridas metodologias de tratamento para correção dos danos e anomalias encontrados.
\end{abstract}

Palavras-chave: Infiltração; Lençol Freático; Patologia; Garagem; Drenagem.

Abstract: Infiltration is among the main pathologies that affect buildings, capable of promoting a series of damages and compromising the performance and safety of construction systems. There are several mechanisms that act for the ingress of moisture, the most common ones resulting from rain, condensation, and capillary rise. However, there are also situations where the water table is shallow in the surroundings of the building or it has subsoil levels close to that layer, a scenario where the occurrence of intense rains and interventions by neighboring buildings may cause the level of water to rise and the appearance of pathological manifestations. In this scenario, the present case study aims to evaluate the manifestations present in the drainage system of a hospital building in the city of Salvador - BA that uses a reservoir system to control the depth of the water table, observing that the level of water in the building region is shallow and there is a 
history of outcrops during the period of intense rain. For diagnosis of pathologies, an on-site visit was carried out with verification and mapping of the entire drainage system and elevator shafts of the building, proceeding with a photographic record, pHmetry test to identify infiltrations. After analyzing the problems found, the possible causes of the identified pathologies are presented, where it was possible to observe the active influence of climatic conditions and the behavior of neighboring buildings for the occurrence of the identified phenomena. At the end, treatment methodologies are suggested to correct the damage and anomalies found.

Keywords: Infiltration; Groundwater; Pathology; Garage; Drainage.

\section{Introdução}

A construção civil é um setor fundamental para o desenvolvimento e crescimento da sociedade, sendo o crescimento acelerado, uso de novos produtos e materiais inovadores com desenvolvimento de novas técnicas construtivas características inerentes ao setor. Contudo, tem-se observado a incidência cada vez maior de manifestações patológicas nos sistemas construtivos. Tais ocorrências estão diretamente relacionadas à perda de desempenho das estruturas, conduzindo-as progressivamente a estados inferiores, podendo atingir níveis críticos onde compromete-se a segurança e usabilidade da edificação (ANTUNES, 2010; DAL MOLIN et al., 2016).

A NBR 15575 (ABNT, 2013) define a vida útil das edificações como o período em que seus elementos e sistemas construtivos apresentam desempenho adequado frente às exigências para as quais foram projetados e construídos, considerando a manutenção periódica. Já a durabilidade pode ser entendida como a capacidade que uma estrutura possui em resistir satisfatoriamente à ação dos agentes degradantes, estando intrinsicamente ligada à sua vida útil, dependendo tanto das variáveis decorrentes da exposição ambiental quanto das condições de uso (SCHULER, 1998).

Caracterizada pela percolação indesejada de água, a infiltração situa-se como uma das principais patologias encontradas nas edificações. Capaz de prejudicar tanto a estrutura quanto os critérios de usabilidade da edificação, a infiltração ocorre em diversos elementos, como pisos, paredes, elementos estruturais, fachadas etc. Dentre as principais manifestações associadas à presença de umidade estão o surgimento de manchamentos, fissurações, desplacamentos, crescimento de microrganismos como bolores e fungos, desenvolvimento de eflorescências e corrosão.

Nas situações em que o nível do lençol freático é raso, tem-se alta probabilidade de ocorrência de infiltração de água nas estruturas e possíveis alagamentos, uma preocupação ainda mais evidente em estruturas enterradas (BURGOS et al., 2017). Tal situação reforça a necessidade de conhecer a profundidade do nível d'água no terreno das construções ainda na fase de projeto, permitindo que sejam adotadas soluções adequadas para controle do nível de água evitando instabilidades no solo e o aparecimento de patologias ao longo da vida útil das estruturas (DA SILVA ROSA et al., 2020).

A NBR 6122 (ABNT, 2019) ressalta a importância do conhecimento sobre a proximidade com o lençol freático para elaboração dos projetos de fundações, observando ainda que qualquer obra que influencie o nível d'água próximo a edificações existentes deve levar em consideração eventuais efeitos deste sobre tais construções. Neste sentido, Soares (2019) acrescenta que as estruturas devem ser projetadas considerando a influência dos esforços hidrostáticos ou dispor de sistemas drenantes apropriados, lembrando ainda que alterações indevidas no nível do lençol podem causar diversos transtornos e até mesmo recalques nas obras vizinhas.

Além da influência mecânica, também deve ser observada a influência química das águas subterrâneas, usualmente mais agressivas do que aquelas advindas das precipitações. Além de atuar como meio para a ocorrência de diversas patologias como a reação álcali-agregado, a água pode conter contaminantes como cloretos e sulfatos, conhecidos agentes agressivos das estruturas de concreto armado. Estes, impulsionados pela pressão do empuxo, podem ser facilmente carreados pelas águas subterrâneas até ingressar nas estruturas, intensificando sua degradação (BURGOS et al., 2017). Sendo, segundo Júnior et al. (2010), 
frequente a ocorrência de fenômenos deletérios no concreto, argamassa e componentes cerâmicos das fundações quando há a contato das estruturas com as águas subterrâneas.

Dentre as diversas técnicas para controle do nível de água do solo, está a utilização de caixas drenantes, que consiste na construção de caixas permeáveis que interceptam a água ascendente e a conduz por tubulações ou canais preenchidos com material drenante até um reservatório de nível, a partir de onde são escoadas para o sistema de drenagem por gravidade ou com auxílio de bombas (JANUÁRIO et al., 2016).

$\mathrm{O}$ uso de veículos aéreos não tripulados (VANT), ou Drones, é uma técnica que tem sido cada vez mais utilizada na construção civil, seja para situações de controle e acompanhamento de obra ou inspeções prediais e avaliações (LISBOA et al., 2018). Os drones facilitam a obtenção de informações de regiões de difícil acesso, onde normalmente seria necessário gasto com locação de equipamentos e ferramentas para realização de inspeções. Neste sentido, tem-se confirmado cada vez mais a eficiência dos drones como ferramenta para identificação de manifestações patológicas e registro de imagens de alta definição que favorecem a tomada de decisão sobre a necessidade de intervenções e ainda permitem que sejam feitos mapeamentos dos danos para acompanhamento das degradações (TONDELO e BARTH, 2019).

O presente estudo de caso teve como objetivo avaliar as manifestações patológicas associadas a problemas de drenagem de um edifício em complexo hospitalar na cidade de Salvador-BA, avaliando as características do sistema e do entorno da edificação, visando identificar as prováveis causas das manifestações observadas e apresentar alternativas para solução.

\section{Metodologia}

A edificação analisada está situada em região com classe de agressividade ambiental tipo III (ABNT NBR 6118:2014), possui aproximadamente 22 anos de construída, estrutura do tipo convencional de concreto armado com paredes de vedação e 15 pavimentos, incluindo estacionamento, lojas e escritórios (Figura 1).

O sistema de drenagem da edificação conta com reservatório de nível para controle da profundidade do lençol freático e foi relatado que o nível do lençol na região da edificação é raso, com histórico da ocorrência de afloramentos durante período de chuvas intensas. A análise foi realizada por meio do estudo dos projetos hidráulicos da garagem e inspeção in loco de todas as caixas do sistema de drenagem no pavimento garagem e poços dos elevadores com captação de imagens em câmera de alto zoom profissional (Sony DSC H400). Também foi realizado teste de pHmetria com solução alcóolica de fenolftaleína associada à termografia infravermelha (câmera FLIR C2 profissional) para detecção de infiltrações e mapeamento de todo o sistema de drenagem da garagem, juntamente com mapeamento da vizinhança com VANT/Drone profissional (DJI Mavic Pro) para avaliar as condições das edificações vizinhas.

Após detecção das anomalias, foi feito o diagnóstico do problema, identificadas as prováveis causas das manifestações encontradas e apresentadas alternativas de solução.

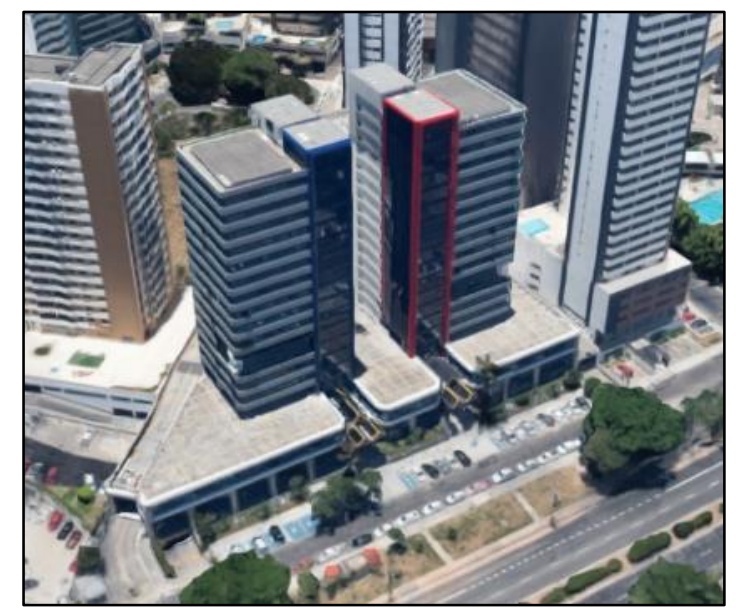

Figura 1 - Vista geral da edificação (Fonte: GoogleMaps) 


\section{Resultados e discussão}

\subsection{Sistema de drenagem}

A Figura 2 mostra o projeto hidráulico da garagem 1, a nível do solo, onde pode ser vista a rede de drenagem e posição das 33 caixas drenantes que escoam para um reservatório de nível. Na Figura 3 pode-se observar o corte das caixas drenantes com suas camadas constituintes e os níveis de escoamento do sistema, sendo projetados três níveis de esgotamento que operam por gravidade, com uma ou duas bombas.

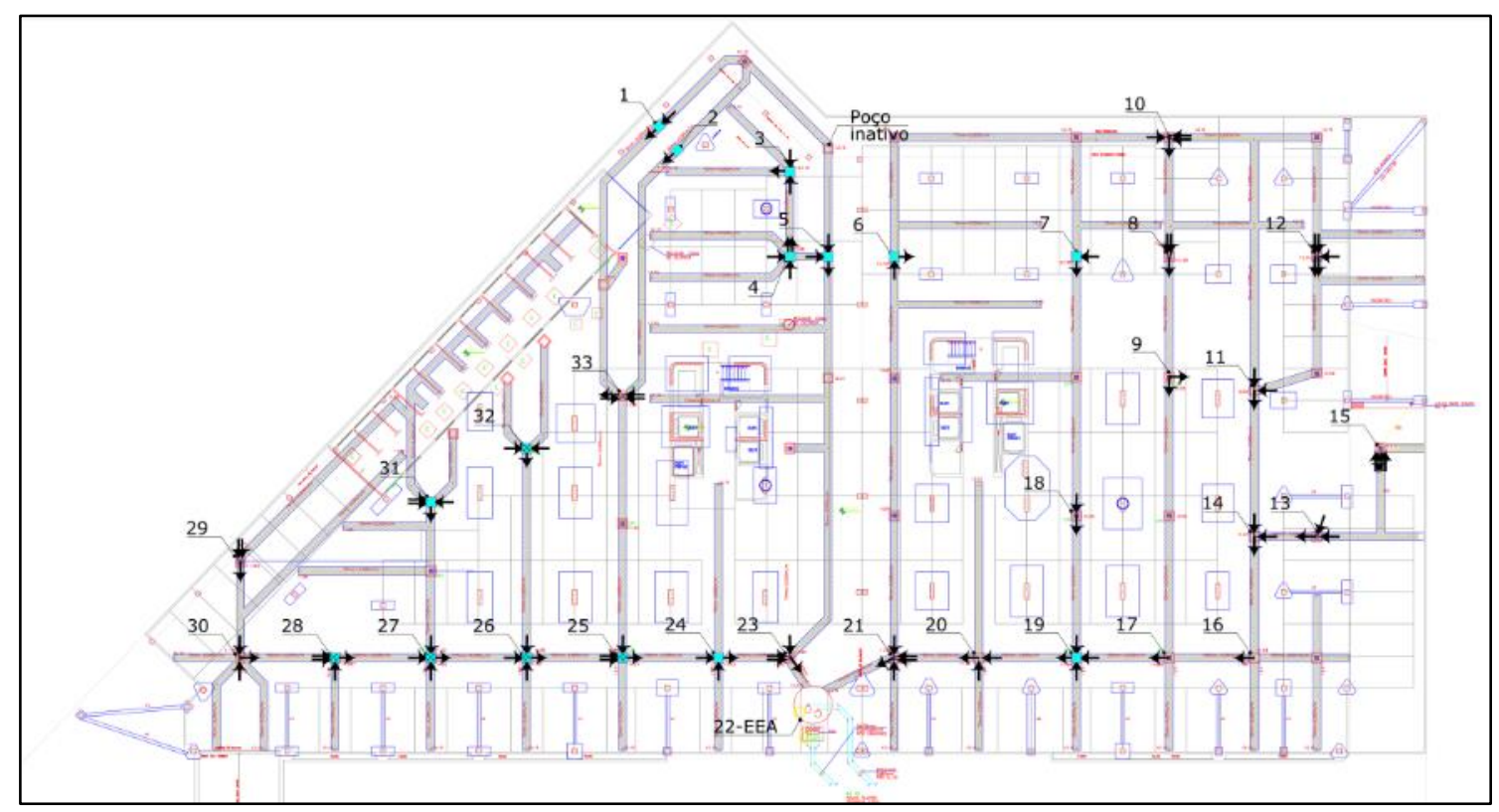

Figura 2 - Projeto hidráulico da garagem
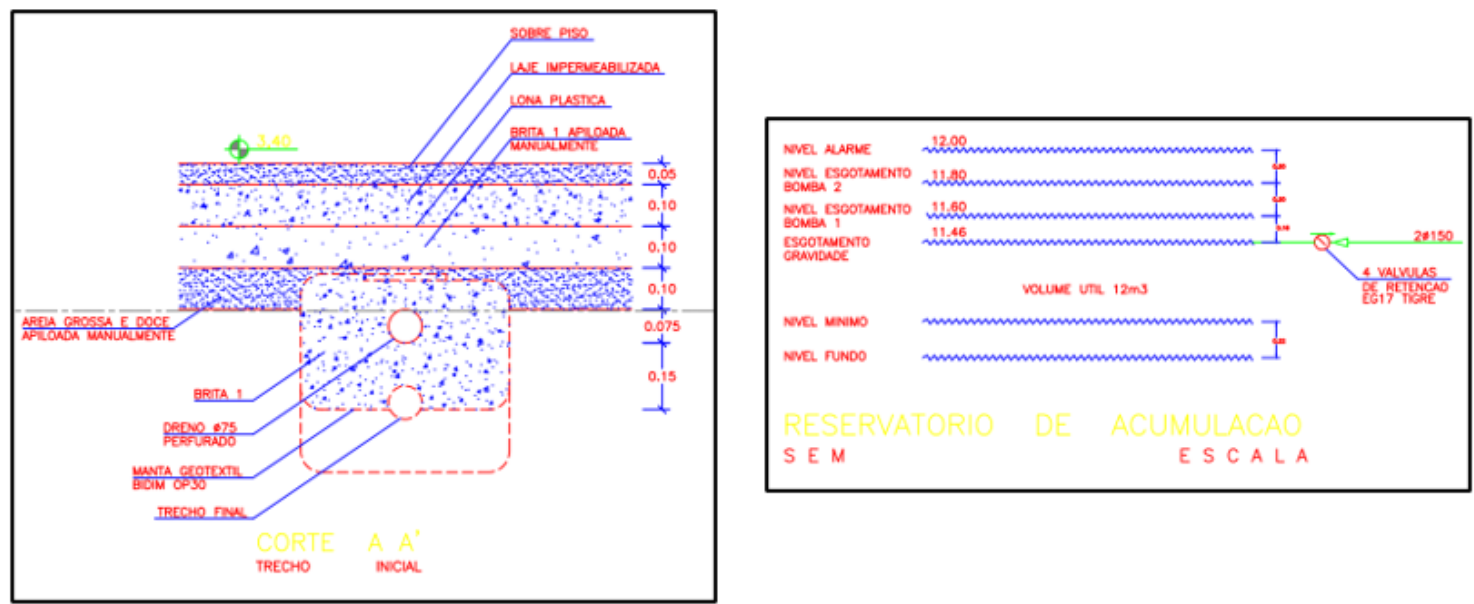

Figura 3 - Corte das caixas drenantes (esq.); Níveis de escoamento do sistema (dir.)

\subsection{Garagem 1}

Durante a vistoria na garagem foi identificado que um dos reservatórios de acumulação (poço artesiano) não estava ativo (Figura 4). Das 33 caixas drenantes, as de número 1 a 7, 19 e 31 estavam com água acumulada (Figura 5), as de número 24, 25, 26 e 32 apresentaram água fluindo (Figura 6), a caixa 27 estava aparentemente obstruída (Figura 7 - esquerda) e as demais, secas (Figura 7 - direita). 


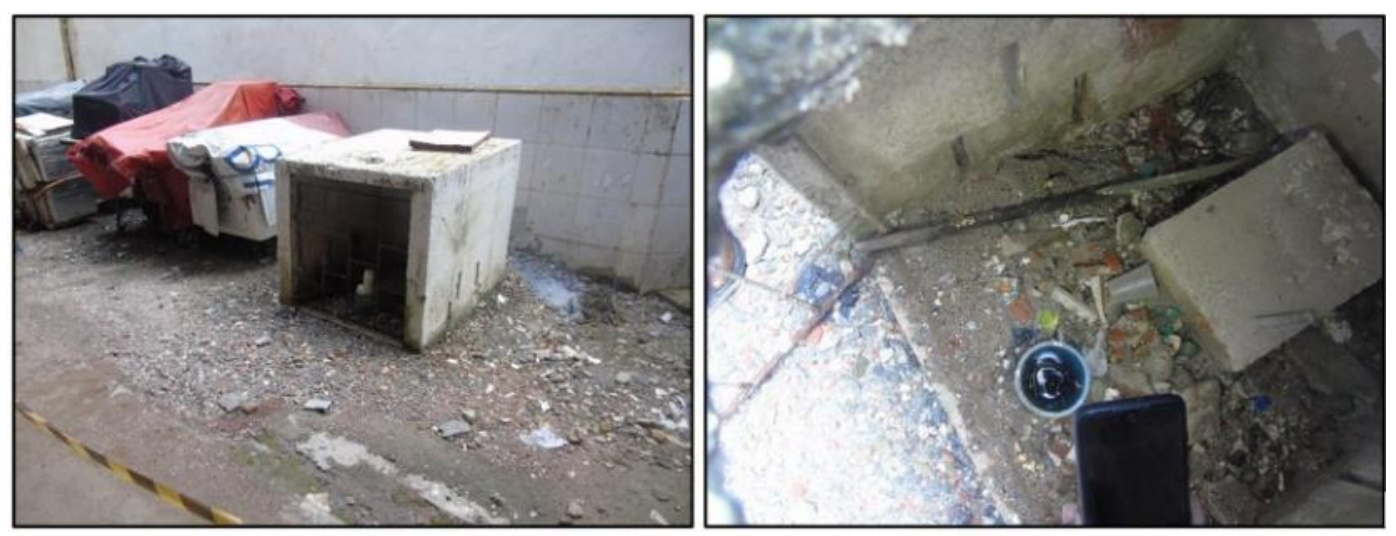

Figura 4 - Poço artesiano desativado

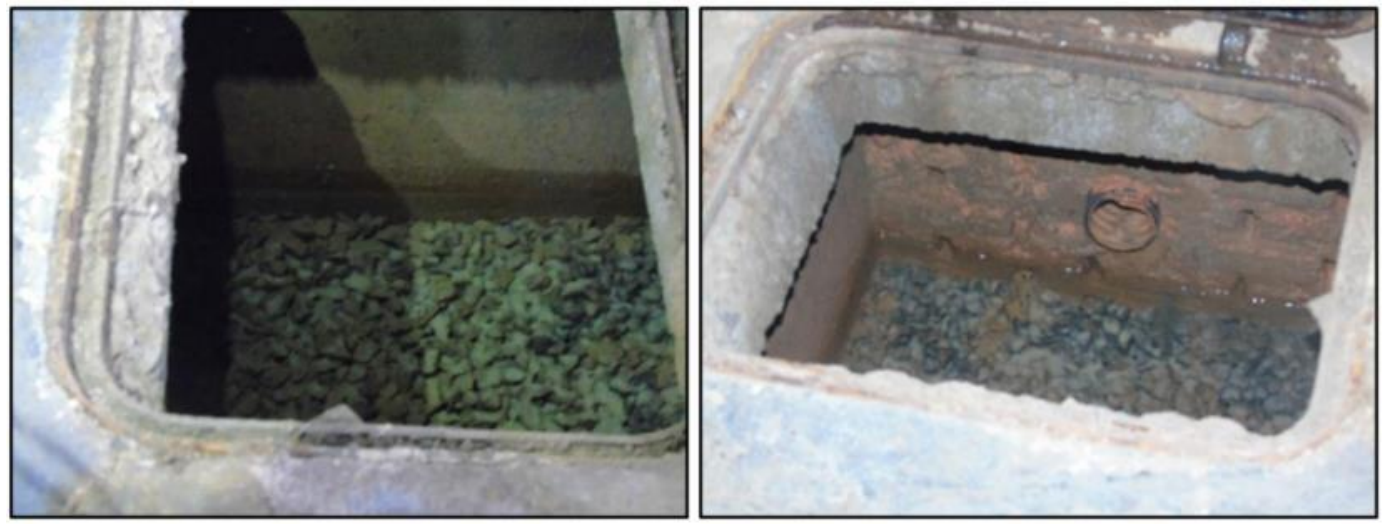

Figura 5 - Caixa 1 (esq.); Caixa 2 (dir.)
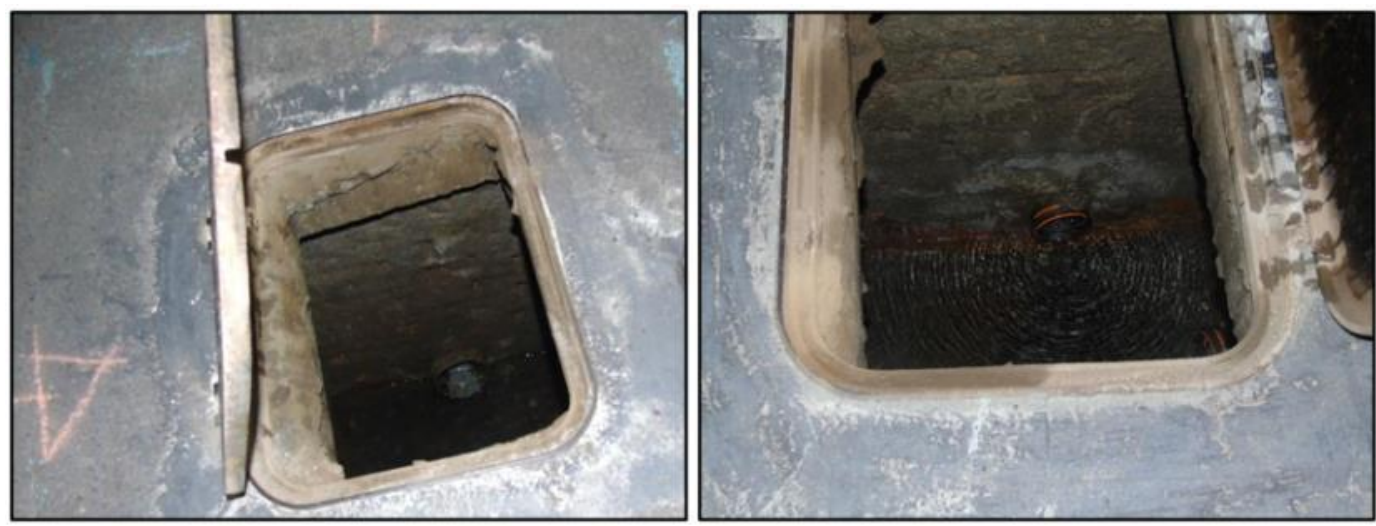

Figura 6 - Caixa 25 (esq.); Caixa 26 (dir.)
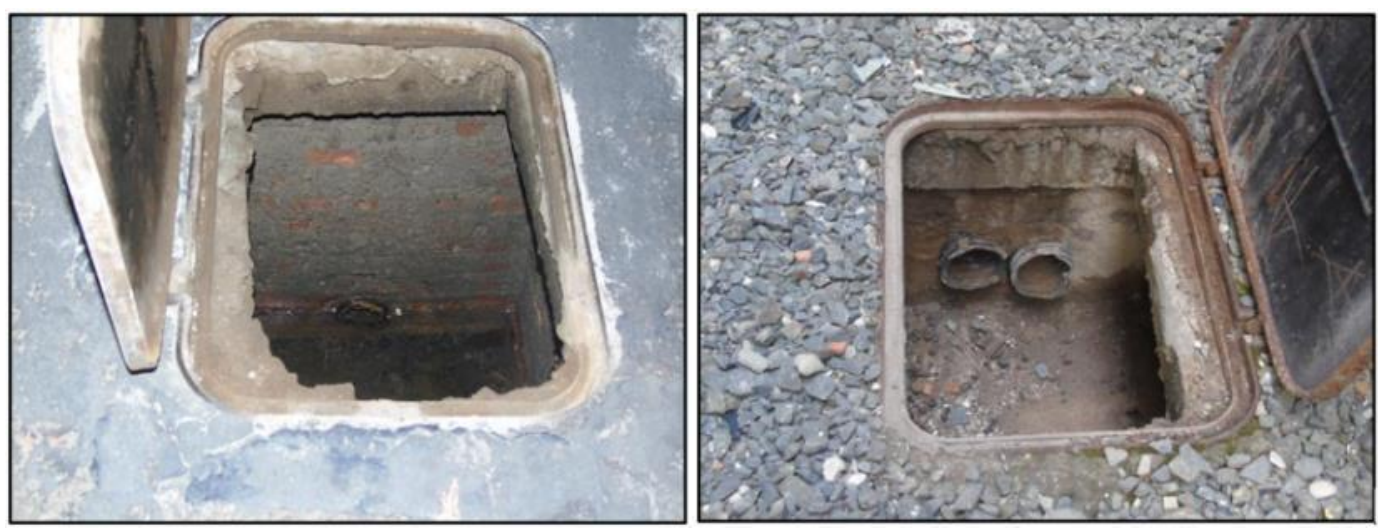

Figura 7 - Caixa 27 (esq.); Caixa 10 (dir.)

3.3 Poço dos elevadores - Torre A

Manifestações patológicas em sistema de drenagem de edificações devido à elevação do lençol freático 
Foram vistoriados todos os poços de elevadores da Torre A, onde se observaram infiltrações no elevador social 3 e no elevador de macas (Figura 8). Em ambos foi realizado ensaio de pHmetria, sendo identificadas regiões infiltrantes com idade recente, caracterizadas pela reação da solução com o hidróxido de cálcio lixiviado, e mais antigas, com coloração branca devido à formação de carbonatos de cálcio pela reação de hidróxido de cálcio com o ar atmosférico. Tal situação evidencia falha no sistema de impermeabilização do poço dos elevadores supracitados, sendo que não foram registradas patologias nos poços dos elevadores sociais 1 e 2 (Figura 9).
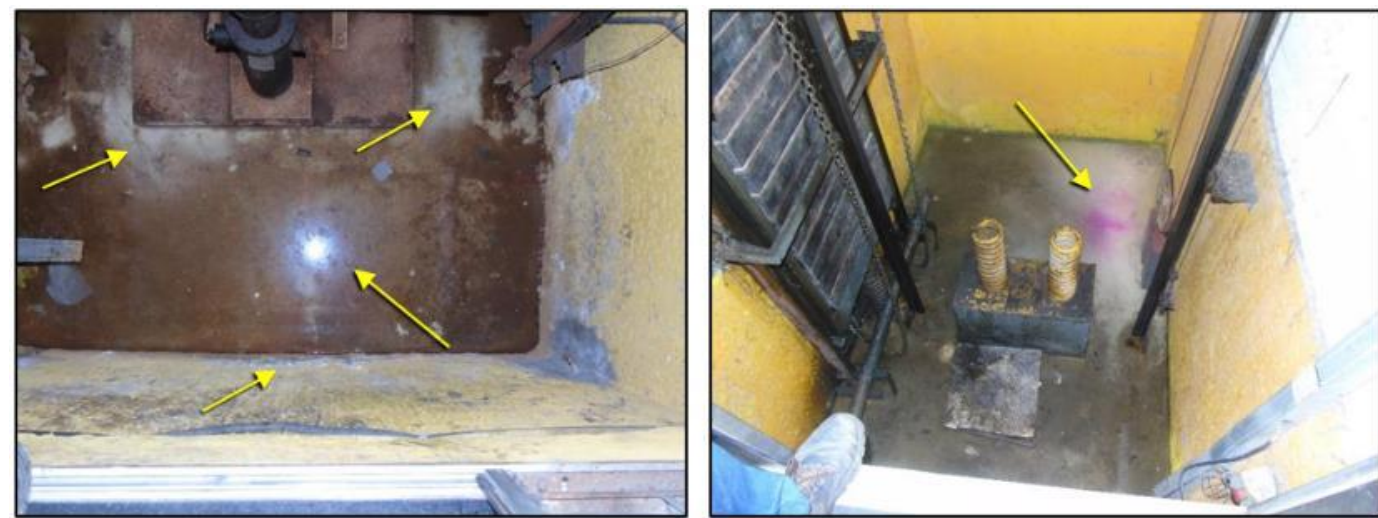

Figura 8 - Acúmulo de água e carbonatos no elevador social 3 (esq.); Infiltração no elevador de macas (dir.)
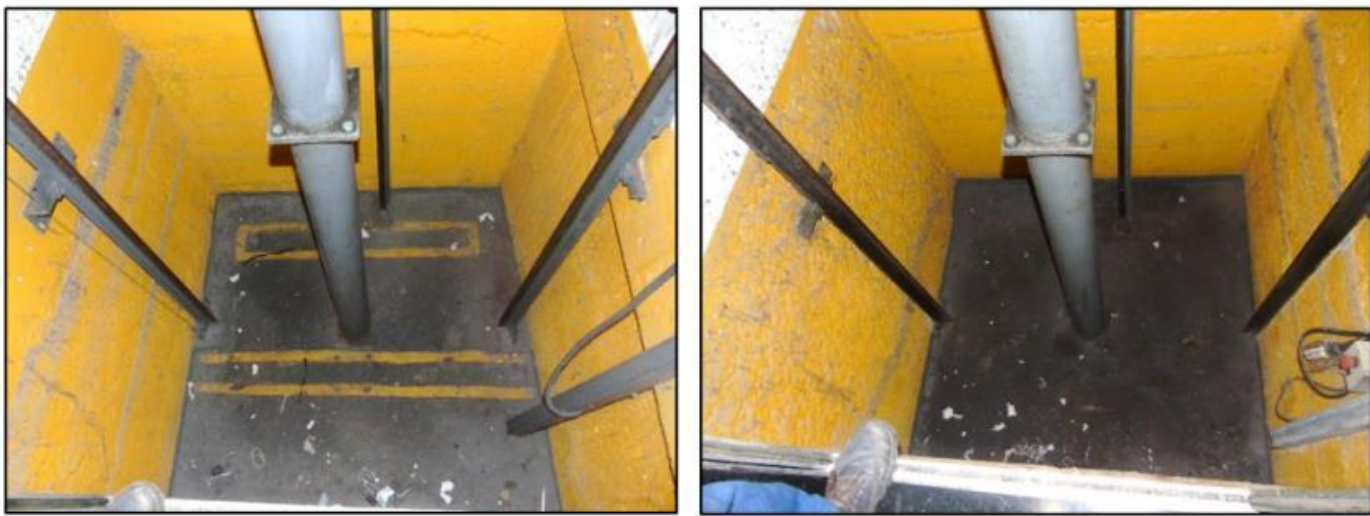

Figura 9 - Poço do elevador social 1 (esq.); Poço do elevador social 2 (dir.)

\subsection{Poço dos elevadores - Torre B}

$\mathrm{Na}$ torre $\mathrm{B}$, foram vistoriados apenas os elevadores sociais, por indisponibilidade de acesso ao elevador de macas. Nestes, foram encontradas infiltrações no elevador social 3, com acúmulo de água (Figura 10). Os poços dos elevadores 1 e 2 não apresentaram manifestações patológicas (Figura 11).
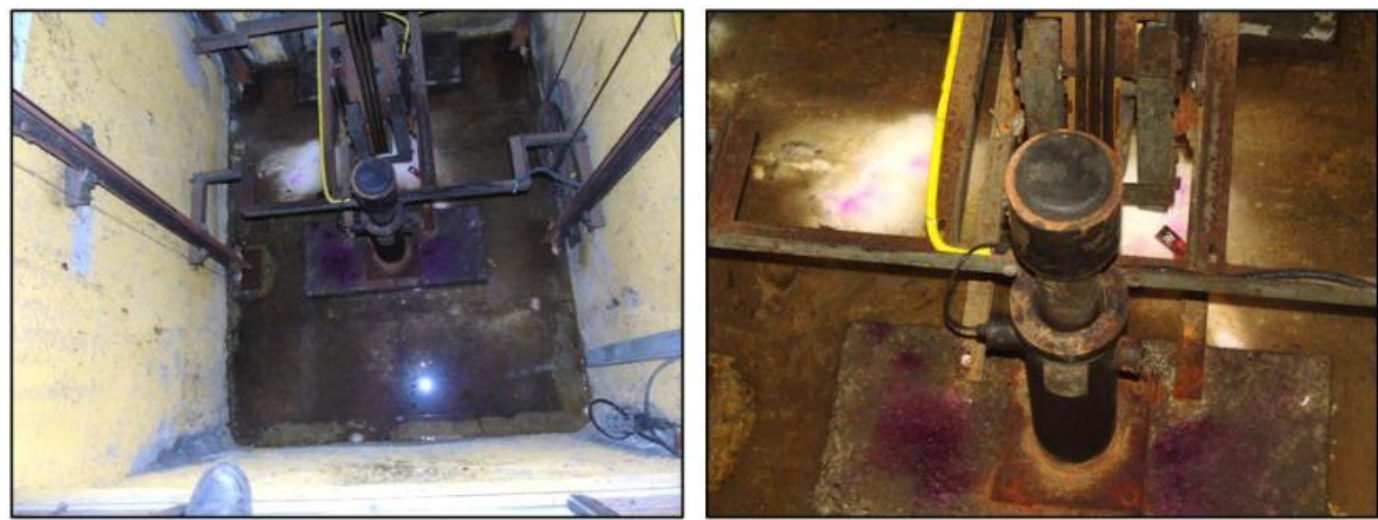

Figura 10 - Elevador social 3 - Acúmulo de água (esq.) e sinais de infiltração (dir.) 

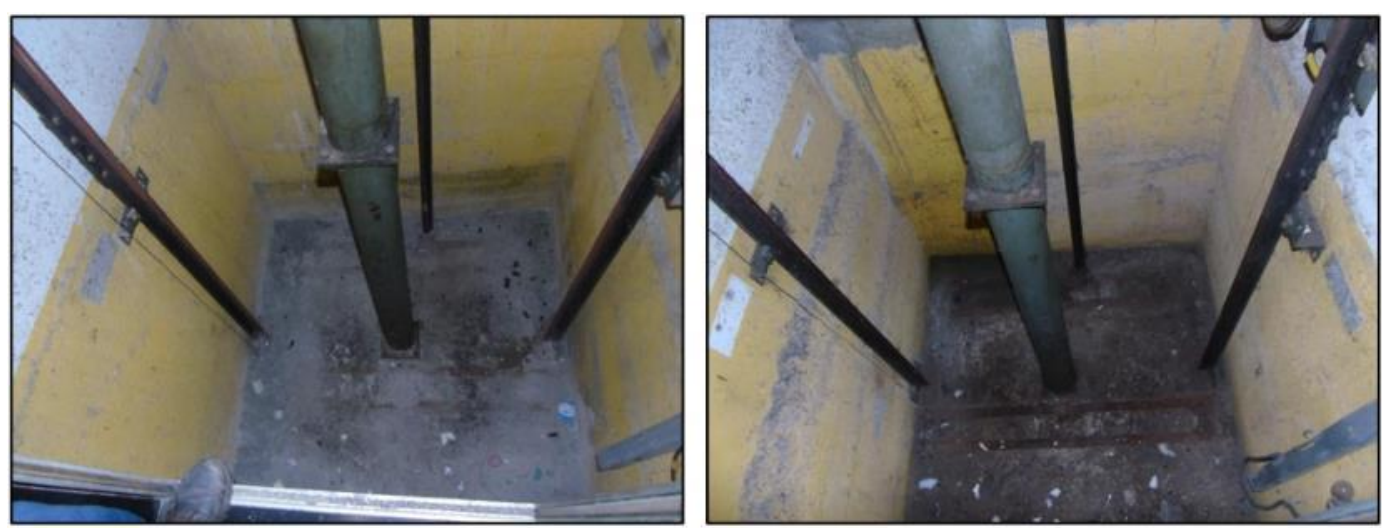

Figura 11 - Elevador social 1 e 2.

\subsection{Entorno do empreendimento}

Foi realizado voo de drone na região posterior da edificação, onde observou-se crescimento de vegetação no muro de contenção (Figura 12 - Esq.) e corrosão no muro de divisão do terreno (Figura 12 - Dir.), situação importante que deve ser avaliada com mais rigor para garantia da estabilidade do talude, principalmente devido à existência de obra no terreno vizinho com acúmulo de material nas proximidades do muro (Figura 13).
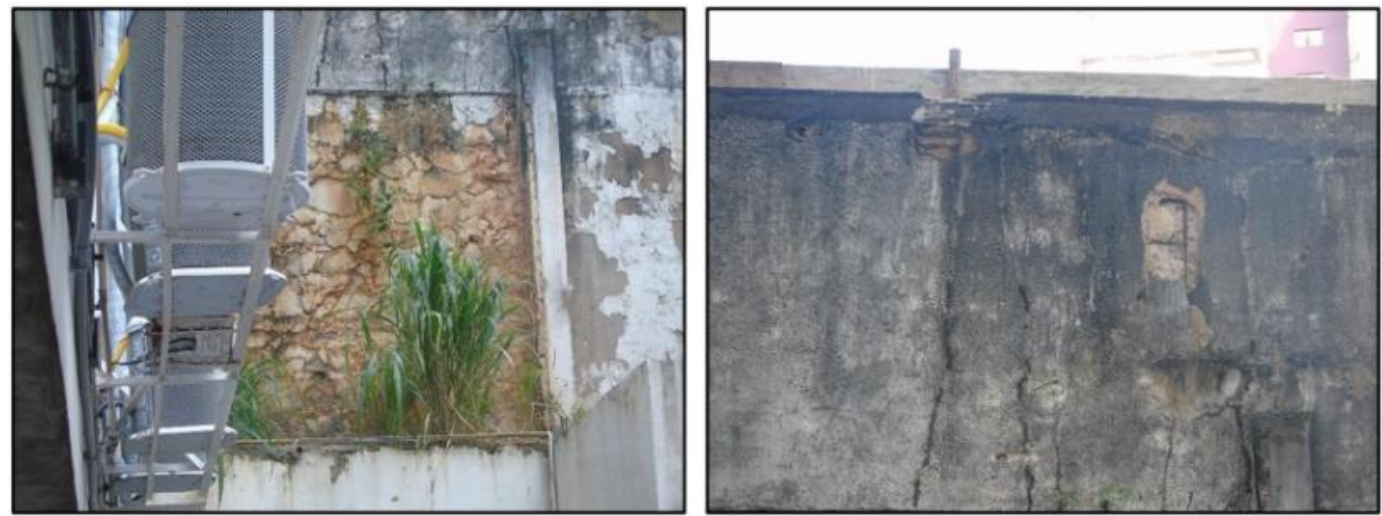

Figura 12 - Muro de contenção - Crescimento de vegetação (esq.); Corrosão das armaduras (dir.)
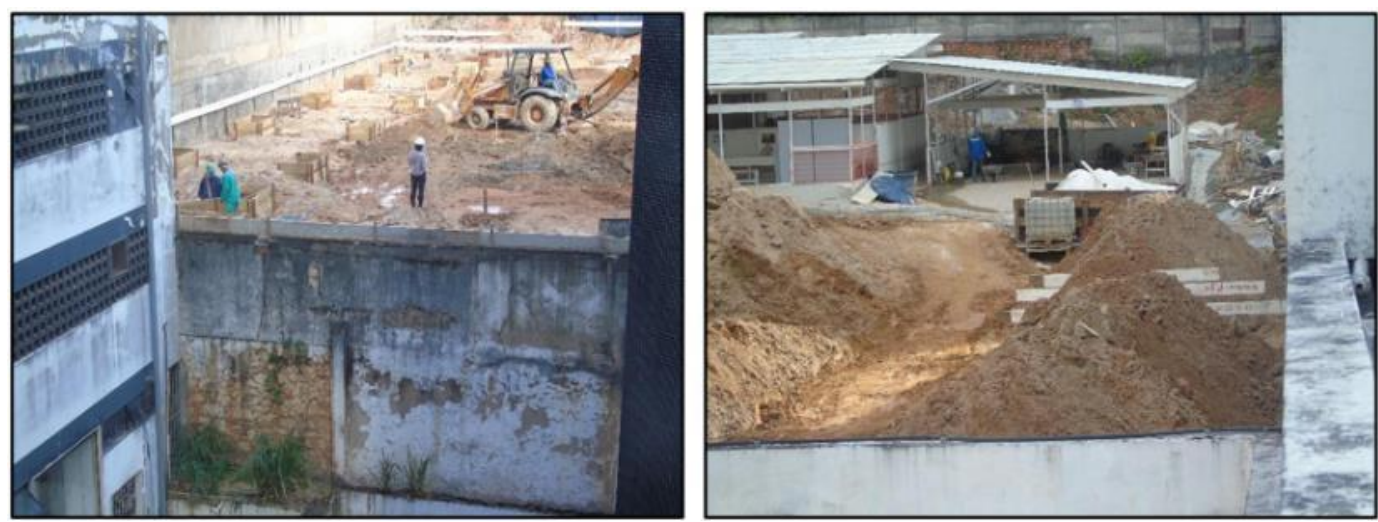

Figura 13 - Obra no terreno vizinho (esq.); Acúmulo de material próximo ao muro de contenção (dir.)

Em visita às outras edificações vizinhas, obteve-se a informação de que o consumo de água de um condomínio adjascente ao complexo hospitalar é oriundo de poço freático, cuja utilização foi interrompida devido às restrições impostas pelas autoridades municipais em função da pandemia de coronavírus, o que promoveu acúmulo de água no aquífero no período da vistoria. 


\subsection{Análises e soluções}

Com base nas evidências encontradas e projetos analisados, pode-se concluir que existe um aquífero raso na região que aflora quando os índices pluviométricos são elevados. Ressalta-se que nos meses de abril e maio de 2020 (período prévio à vistoria) houve, segundo dados do Instituto do Meio Ambiente e Recursos Hídricos (INEMA), uma precipitação pluviométrica acumula da de $400 \mathrm{~mm}$ em cada mês, conforme pode ser visto na Figura 14, sendo a maior média histórica dos últimos 20 anos.

Além disso, a mudança no consumo de água do poço freático da edificação vizinha ao prédio vistoriado favoreceu o aumento da quantidade de água no aquífero, o que contribuiu para a infiltração observada nos poços de elevador com sistema de impermeabilização deficiente, sendo informado por funcionário da edificação que é necessária drenagem manual da água dos poços de elevadores diariamente. Ademais, não foram encontrados indícios de danos estruturais ou presença de fissuras na estrutura.
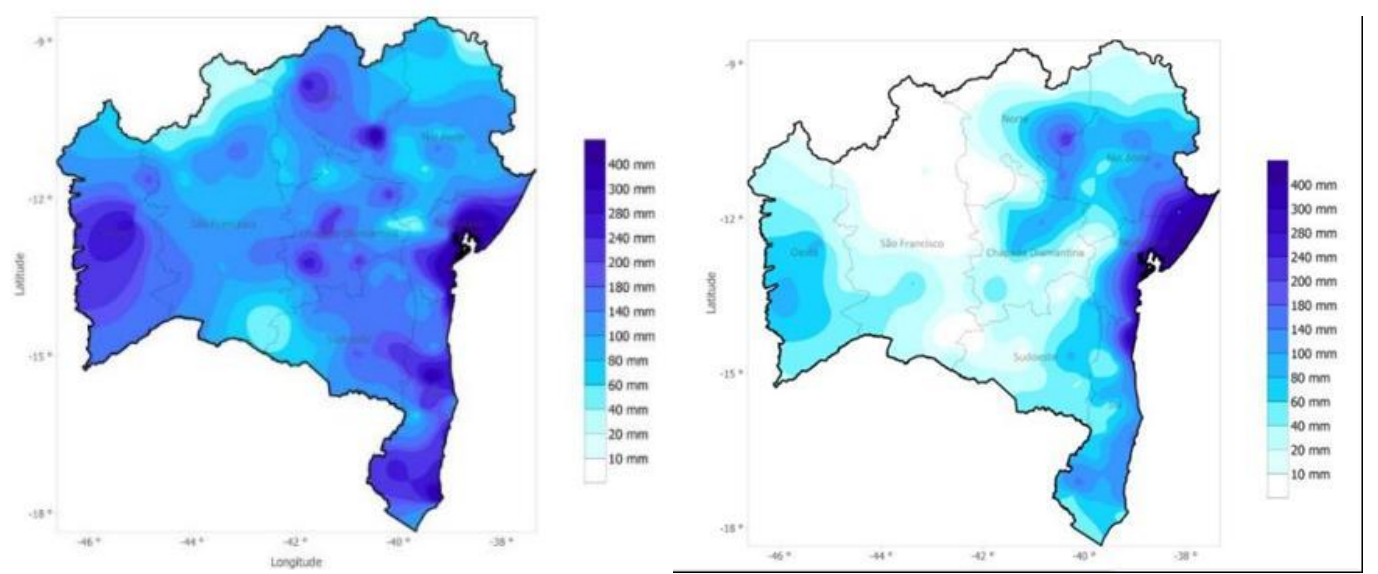

Figura 14 - Índice pluviométrico acumulado na Bahia - abril (esq.); maio (dir.). Fonte: INEMA (2020a, 2020b)

Dado o exposto, recomenda-se que seja realizada limpeza completa da tubulação do sistema de drenagem, visando principalmente a desobstrução das caixas drenantes. Também se recomenda a transformação do poso artesiano desativado em um reservatório de nível, com bombas, para melhor controle do nível do lençol freático. Também deve ser refeita a impermeabilização dos poços dos elevadores, de preferência com sistema semiflexível que seja resistente a pressões negativas do subsolo.

É importante que seja feita a recuperação do mudo dos fundos, com remoção da vegetação e tratamento da corrosão das armaduras. Para tratamento da corrosão, deve-se escarificar o concreto expondo a armadura até uma profundidade de 10 a $15 \mathrm{~mm}$ por trás das barras de aço, o suficiente para possibilitar a remoção da oxidação nas barras por lixamento e aplicação de primer anticorrosivo. É de extrema importância que seja verificada a perda de seção da armadura, sendo consultado engenheiro estruturalista para determinação da necessidade de reforços e avaliação da estabilidade antes da realização de intervenções.

\section{Conclusões}

Após análise dos problemas encontrados, observou-se que as infiltrações registradas foram principalmente resultantes da falta de manutenção adequada do sistema de drenagem associado a um aumento do volume no aquífero local, dado o menor consumo na vizinhança e maior regime pluviométrico no período.

O observado evidencia a importância do dimensionamento adequado e contínua manutenção do sistema drenante, visto que obstruções no fluxo de água e o mal funcionamento do sistema de esgotamento podem provocar elevações nos níveis do lençol freático e danos às estruturas devido à percolação de água. Destacase também que o bom desempenho da edificação está relacionado ao bom funcionamento do sistema de drenagem e este não deve ser dependente da ocorrência favorável de fatores externos como o consumo de água por parte das edificações vizinhas. 
De forma geral, os danos observados foram pequenos, sem sinais de corrosão ou fissuração da estrutura. Ainda assim, é importante que as medidas corretivas sejam realizadas com celeridade para evitar futuros problemas e o avanço do estado de degradação, associado a elevados custos de manutenção corretiva, que venham a comprometer a usabilidade e segurança da edificação.

\section{Agradecimentos}

Agradecemos à Fundação de Amparo à Pesquisa do Estado da Bahia (FAPESB) pelo apoio financeiro e incentivo à pesquisa.

\section{Referências Bibliográficas}

ABNT - Associação Brasileira de Normas Técnicas. (2013). NBR 15575-1: Edificações habitacionais Desempenho Parte 1: Requisitos gerais, Rio de Janeiro.

ABNT - Associação Brasileira de Normas Técnicas. (2014). NBR 6118: Projeto de estruturas de concreto Procedimento, Rio de Janeiro.

ABNT - Associação Brasileira de Normas Técnicas. (2019). NBR 6122: Projeto e execução de fundações, Rio de Janeiro.

Antunes, G. R. (2010) Estudo de manifestações patológicas em revestimento de fachada em Brasília sistematização da incidência de casos. Dissertação de Mestrado. Universidade de Brasília, Brasília.

Burgos, R. D. F., Lins. E. J. M., Bezerra, R. S., Monteiro, E. C. B. A Influência Das Precipitações Pluviais E Do Nível Do Lençol Freático Nos Túneis Urbanos Da Cidade Do Recife. In: Conferência Nacional De Patologia E Recuperação De Estruturas - CONPAR, 2017, Recife. 2017.

Da Silva Rosa, D., Silva, P. C. O., Barros, W., Rocha, M. M. M. (2020). REBAIXAMENTO DE LENÇOL FREÁTICO: análise do método executivo empregado na construção da ETE Santinho em Ribeirão das Neves. PARAMÉTRICA, 12(13).

Dal Molin, D. C. C., Masuero, A. B., Andrade, J. J. O, Possan, E., Masuero, J. R., Mennucci, M. M. (2016). Contribuição à Previsão da Vida Útil de Estruturas de Concreto. Avaliação de Desempenho de Tecnologias Construtivas Inovadoras: Materiais e Sustentabilidade. p. 223-270. Editora Scienza.

INEMA - Instituto do Meio Ambiente e Recursos Hídricos. (2020a). Boletim Mensal de Monitoramento Hidrometeorológico da Bahia - Abril 2020. Disponível em http://www.inema.ba.gov.br/wpcontent/uploads/2020/05/4-2020-Monitoramento-Mensal.pdf. INEMA.

INEMA - Instituto do Meio Ambiente e Recursos Hídricos. (2020b). Boletim Mensal de Monitoramento Hidrometeorológico da Bahia - Maio 2020. Disponível em http://www.inema.ba.gov.br/wpcontent/uploads/2020/06/5-2020-Monitoramento-Mensal-1.pdf. INEMA.

Januário, N. F., Garcia, P. R., Garcia, G. F. (2016). Rebaixamento do lençol freático. Revista Brasileira de Ciência, Tecnologia e Inovação, 1(3), 66-81.

Júnior, F. C. Z. et al. Patologias de Fundações de Edifícios Causadas por Ações Ambientais. In: VI Congreso Internacional Sobre Patologia Y Recuperacion De Estructuras (CINPAR), Córdoba-Argentina. 2010.

Lisboa, D. W. B., Da Silva, A. B. S., De Souza, A. B. A., Da Silva, M. P. (2018). Utilização de VANT na inspeção de manifestações patológicas em fachadas de edificações. Congresso Técnico Científico da Engenharia e da Agronomia, Maceió.

Schuler, A. (1998). Caracterização de argamassas com adições de sílica ativa como material para reparos e reforços de estruturas de concreto armado. Dissertação (Mestrado). Curso de Pós-graduação em Engenharia Civil, Universidade Federal do Rio Grande do Sul, Porto Alegre.

Soares, D. M. "Análise De Lajes De Subpressão Em Obras De João Pessoa-PB." Trabalho de Conclusão de Curso. Universidade Federal da Paraíba. 57 p. 2019.

Tondelo, P. G., Barth, F. (2019). Análise das manifestações patológicas em fachadas por meio de inspeção com VANT. PARC - Pesquisa em Arquitetura e Construção, v. 10. 